\title{
Communication and relationship at time of COVID-19: a possible heritage
}

\author{
Elena Vegni ${ }^{1,2}$ (1) $\cdot$ Federica Bonazza $^{1} \cdot$ Lidia Borghi $^{1} \cdot$ Giulia Lamiani $^{1}$
}

Received: 9 September 2021 / Accepted: 17 November 2021 / Published online: 23 January 2022

(c) The Author(s), under exclusive licence to Società Italiana di Medicina Interna (SIMI) 2021

\section{Dear Editor,}

For many years now, the medical profession has recognised the importance of communication and relational skills as a part of professional competence. These skills are anchored to a multidimensional, biopsychosocial concept of health, as stated by the World Health Organization (WHO) [1]. The long period of pandemic — which has solicited medical science and challenged health systems in many ways-has further emphasized the fundamental role of relationship in medical care. During the pandemic, doctors have experienced firsthand the power (and the fatigue) of the therapeutic relationship [2]. Here, we would like to further explore this matter.

First of all, we think that the increased attention to the doctor-patient relationship during the pandemic was due to two factors. The first one was the absolute isolation the patients were confined to. Isolation was a necessary yet extreme measure that deprived patients of any relationship except the one with their doctors and the other healthcare professionals. Therefore, a previously dormant awareness has emerged of how essential this contact is. "Being with the patient" has been recognised as an important source of cure, yet not cost-free. The second factor was the lack of a therapeutic strategy, and the consequent uncertainty, that has characterised the approach to COVID19 patients for many months. Doctors, having to care for these patients with 'blunt weapons' (to use a war metaphor often applied to the pandemic), had to rely on the only thing that remained solid, namely their relational knowledge.

Elena Vegni

elena.vegni@unimi.it

1 Department of Health Sciences, University of Milan, Via A. di Rudinì 8, 20142 Milan, Italy

2 ASST Santi Paolo e Carlo, San Carlo Hospital, Via Di Rudinì 8, 20142 Milan, Italy
A second matter concerns communication skills. During the pandemic, doctors experimented their communication skills in previously unknown ways. Speech-with the face covered by safety devices, had to follow new paths: sentences had to be concise, clear, and loud; those pronounced by the patient, checked out. At the same time, physicians deeply understood through experience-not just cognitively-the relevance of nonverbal communication. This led to the choice of writing their names in capital letters on the protective coveralls, the necessary intensity of a gaze due to the impossibility to touch, or the use of the tone of voice to convey closeness and compassion. In addition, doctors had to consciously learn to manage verbal communication with family members over a telephone or a tablet. The enforced social distancing has, for sure, led to a better understanding of those publications suggesting the importance of preparing for a conversation, finding a private place to call a relative, or frequently checking the comprehension of the information given. The literature on communicating bad news had to be resumed, remodelled, and consumed by doctors who had previously considered these aspects as superfluous, nontherapeutic or just as good social practice.

A third and last, but not least, matter concerns the inner life of doctors [3]. The pandemic has exposed doctors to a scenario of fear, uncertainty and insecurity that only a few of them had previously experienced in the context of disaster medicine or humanitarian emergencies. Of course, the extraordinary scientific progress, which has made effective treatments and vaccines available within a very short time, has to be acknowledged. Yet, it is difficult to deny the extent to which, for the first time in a pandemic and uncircumscribed way, doctors have experienced the helplessness resulting from not knowing what to do, and the fear deriving from not feeling safe themselves in the healthcare context. In the pre-pandemic era, it was difficult to give space to the inner life of doctors in clinical practice and medical education. In the past, doctor's inner life was either medicalised (as for the few sufferings from burnout 
or psychopathological disorders, e.g. addiction) or marginalised as it was considered as a weakness to be kept hidden from others, especially if this meant seeking professional help. During the pandemic, an exponential number of papers have explored the inner experience of clinicians and raised awareness about the risk of psycho-emotional sufferings, which can range from post-traumatic stress disorder to moral distress [4]. The importance given to this "psychological emergency" resulted in an effort by healthcare institutions to support clinicians through debriefing or defusing activities and psychological interventions [5]. More research is needed to assess the efficacy of the actions implemented. However, the pandemic increased the awareness that only those who are cared for and look after themselves, can in turn offer adequate care, which is made not only of biomedical knowledge but also of relational readiness.

In conclusion, it is not yet possible to know whether and how we will treasure these acquisitions. We are still in the thick of the pandemic while we are wishing to get out of it quickly and archive it in the memory of history. However, we believe there is a question that we need to answer collectively as healthcare professionals. Are we going to, at last, confer professional dignity to the act of caring for relationships and caring for those who care in healthcare? As clinical psychologists, we strongly support the wish for a systematic, and not occasional, training of healthcare professionals in therapeutic relationships. This should take place in the undergraduate curriculum, with special courses for the teachings of relational and communication skills; in continuing healthcare education, with a constant attention to the complexity of difficult conversations; and in the daily clinical work where it is our duty to preserve a professional attention to the relationships between patients, families and the healthcare team. Perhaps the pandemic offered an opportunity to change our clinical practice and we should not let it fade away.

Author contributions EV wrote the first draft of the study; all the authors critically revised the manuscript and approved the final version.
Funding No funding to declare.

Availability of data and material Not applicable.

Code availability Not applicable.

\section{Declarations}

Conflict of interest The authors declare that they have no conflict of interest.

Human and animal rights statement Not applicable.

Informed consent Not applicable.

\section{References}

1. World Health Organization (1948) Health Promotion Glossary. https://www.who.int/healthpromotion/about/HPR\%20Glossary\% 201998.pdf. Accessed 1 September 2021

2. Stewart M, Brown JB, Donner A, McWhinney IR, Oates J, Weston WW, Jordan J (2000) The impact of patient centered care on outcomes. J Fam Pract 49:796-804

3. Meier DE, Back AL, Morrison RS (2001) The inner life of physicians and care of the seriously ill. JAMA 286:3007-3014. https:// doi.org/10.1001/jama.286.23.3007

4. Lamiani G, Borghi L, Poli S, Razzini K, Colosio C, Vegni E (2020) Hospital employees' well-being six months after the COVID-19 outbreak: results from a psychological screening program in Italy. Int J Environ Res Public Health 18:1-12. https:// doi.org/10.3390/ijerph18115649

5. Leone D, Borghi L, Bonazza F et al (2020) Interventi psicologici in ospedale ai tempi della CoViD-19: una panoramica delle realtà proposte dalle Unità Operative di Psicologia (UOPSI) della Lombardia. Recenti Prog Med 111:593-601. https://doi.org/10.1701/ 3453.34419

Publisher's Note Springer Nature remains neutral with regard to jurisdictional claims in published maps and institutional affiliations. 